\title{
KESESUAIAN RESEP DENGAN STANDAR PELAYANAN MEDIS DAN FORMULARIUM JAMKESMAS PADA PASIEN RAWAT JALAN JAMKESMAS
}

\author{
Dian Medisa ${ }^{1}$, Sulanto Saleh Danu ${ }^{2}$, Rustamaji $^{2}$ \\ ${ }^{1}$ Program Studi Profesi Apoteker, Universitas Islam Indonesia, Yogyakarta \\ ${ }^{2}$ Fakultas Kedokteran, Universitas Gadjah Mada, Yogyakarta \\ e-mail : dianmedisa@gmail.com
}

\begin{abstract}
ABSTRAK
Dalam rangka memenuhi kebutuhan pelayanan kesehatan bagi masyarakat miskin, pemerintah Indonesia mencanangkan program Jamkesmas berbasis DRGs (Diagnosis Related Groups) yang bertujuan untuk meningkatkan akses masyarakat miskin terhadap pelayanan kesehatan yang berkualitas. Pelayanan kesehatan pada program ini berbasis pada Standar Pelayanan Medis dan Formularium Jamkesmas. Banyak hal yang dapat mempengaruhi peresepan rasional di pelayanan medis. Sehingga penelitian ini bertujuan untuk mengetahui kesesuaian resep dengan Standar Pelayanan Medis dan Formularium Jamkesmas. Penelitian ini menggunakan metode observasional pada 10 besar penyakit di salah satu Rumah Sakit di Daerah Istimewa Yogyakarta (RS X). Kesesuaian peresepan dilihat secara kuantitatif dari prosentase kesesuaian dengan menggunakan data resep rawat jalan pasien jamkesmas serta secara kualitatif dengan wawancara mendalam. Penghitungan data resep menggunakan rumus indikator penggunaan obat dari World Health Organization (WHO). Persentase kesesuaian resep dengan SPM pada tiap 10 besar penyakit di RS X bervariasi mulai dari $24,3 \%$ pada penyakit CHF sampai $82 \%$ pada penyakit DM, sedangkan persentase obat yang diresepkan sesuai dengan formularium Jamkesmas mulai dari $49 \%$ pada penyakit vertigo sampai $96 \%$ pada penyakit hipertensi. Jumlah rata-rata obat per resep 2,7; persentase peresepan obat generik sebesar $85,7 \%$, persentase obat antibiotik $23,3 \%$, persentase obat injeksi $22,0 \%$, dan persentase obat yang masuk DOEN $76,7 \%$. Resep yang diteliti pada 10 besar penyakit belum sepenuhnya sesuai dengan SPM dan formularium Jamkesmas.
\end{abstract}

Kata Kunci: Formularium Jamkesmas, DRGs, SPM, kesesuaian

\section{ABSTRACT}

Health is rights of every human. In Indonesia, poor people had difficulty to access health services. Therefore government creates a program called "Jamkesmas" which based on DRGs (Diagnosis Related Groups) to improve quality of health services. Physicians should prescribe medicines according to the diagnosis and Jamkesmas formulary. The compliance between prescription with Standard Treatment Guidelines (STGs) and Jamkesmas formulary is a must. The aim of this research was to know the prescriptions compliance to STGs and Jamkesmas formulary. This research was observational study using prescriptions of Jamkesmas's outpatients . Furthermore, qualitative data with in-depth interviews was used to further analysis. Quantitative data were calculated by using drug use indicators for the percentage of prescriptions compliance. The percentage of prescriptions compliance with STGs in each of 10 diseases in once of hospital in Daerah Istimewa Yogyakarta (Hospital X), started from $24.3 \%$ in CHF to $82 \%$ in DM diseases, whereas prescriptions compliance with Jamkesmas Formulary was started from $49 \%$ in vertigo to $96 \%$ in hypertension diseases. Average number of drugs per prescription was 2.7 and the most of drugs $(85.7 \%)$ were prescribed by its generic names; $23.3 \%$ of prescriptions contained antibiotic and 22.0\% contained of injectable drug. Percentage of drugs prescribed from essential medicines list was $76.7 \%$. The prescriptions of 10 diseases were not fully compliance to Standard Treatment Guidelines and Jamkesmas formulary. 
Keywords: Jamkesmas formulary, DRG, STGs, compliance

\section{PENDAHULUAN}

Seiring dengan perkembangan dan pertumbuhan masyarakat, pelayanan kesehatan yang rasional harus mempertimbangkan efektivitas, keamanan, kesesuaian, dan keterjangkauan secara ekonomi. Di Indonesia, pelayanan kesehatan masih belum dapat diakses oleh sebagian besar masyarakat yang memiliki pendapatan rendah. Pemerintah membuat berbagai program dan kebijakan tentang pendanaan, seperti program jaminan kesehatan sosial, sebagai upaya untuk meningkatkan akses masyarakat terhadap pelayanan kesehatan serta mengatasi masalah kesehatan masyarakat miskin. Salah satu program tersebut adalah Jamkesmas (Jaminan Kesehatan Masyarakat) yang telah dilaksanakan oleh Kementerian Kesehatan sejak tahun 2008. Pelaksanaan Program Jamkesmas juga untuk meningkatkan kualitas pelayanan kesehatan dengan memberlakukan sistem Diagnosa Related Groups (DRGs) atau kasus campuran (casemix) (Fijn, 2001; Anonim, 2008).

Meskipun telah melaksanakan sistem DRGs, pemerintah tetap membuat formularium Jamkesmas untuk mengendalikan mutu dan biaya pengobatan. Selain itu, untuk meningkatkan mutu dan cost-effectiveness pelayanan kesehatan digunakan Standar Pelayanan Medis (SPM) atau standar pengobatan dari masing-masing rumah sakit yang bersangkutan. Standar Pelayanan Medis digunakan sebagai pedoman terapi dan salah satu dasar dalam pembuatan clinical pathway yang kemudian digunakan untuk menentukan biaya pengobatan sesuai dengan Indonesia Diagnosis Related Group (INA-DRG) (Anonim, 2010a; Adisasmito, 2008).

Rumah Sakit $X$ mulai melaksanakan program Jamkesmas berbasis tarif paket INADRG pada tahun 2008. Pada pelaksanaan Jamkesmas, dokter harus menuliskan resep obat sesuai dengan SPM dan formularium Jamkesmas. Hal tersebut disebabkan karena pada pasien Jamkesmas, tarif paket diberikan berdasarkan klasifikasi penyakit yang diderita pasien. Tarif paket merupakan biaya keseluruhan meliputi jasa pelayanan, tindakan, pemeriksaan penunjang, obat-obatan, dan bahan habis pakai, sehingga dalam memberikan pelayanan kesehatan pada pasien Jamkesmas, dokter harus memberikan pengobatan sesuai diagnosis pasien dengan mengacu pada SPM. Peresepan obat kepada pasien Jamkesmas juga harus sesuai dengan formularium Jamkesmas, karena obat yang terdapat dalam formularium Jamkesmas merupakan obat yang telah terbukti efektif, aman, dan terjangkau, sehingga pemerintah menggunakannya untuk pengendalian mutu dan biaya pelayanan kesehatan. Apabila peresepan tidak sesuai dengan SPM dan formularium Jamkesmas, maka dapat menyebabkan pengobatan yang tidak efektif dan biaya pengobatan jadi mahal (Anonim, 2008; Adisasmito, 2008; Anonim, 2010a).

Kesesuaian resep obat dengan formularium dan SPM atau standar pengobatan termasuk dalam indikator penggunaan obat menurut WHO. Pada penelitian oleh Fitriah 
(2012), diperoleh data kesesuaian resep pasien umum dengan SPM pada penyakit LBP $71 \%$, TBC $71,7 \%$, dan ISK 54,7\% serta kesesuaian resep pasien rawat jalan umum dengan formularium rumah sakit pada penyakit LBP 88,23\%, TBC 100\%, dan ISK 94,27\%. Hasil tersebut menunjukkan bahwa resep obat belum sepenuhnya sesuai dengan SPM dan formularium rumah sakit, kecuali resep pada penyakit TBC. Hal tersebut secara tidak langsung menggambarkan adanya ketidaksesuaian peresepan dengan SPM dan formularium. Ketidaksesuaian peresepan dengan SPM dan formularium Jamkesmas dapat disebabkan oleh beberapa hal. Berdasarkan latar belakang di atas, maka peneliti akan melakukan penelitian tentang kesesuaian resep dengan SPM dan formularium Jamkesmas pada pasien rawat jalan Jamkesmas di RS X.

\section{METODE PENELITIAN}

\author{
Penelitian ini merupakan penelitian \\ observasional menggunakan pendekatan \\ kuantitatif dan kualitatif. Data kuantitatif \\ diperoleh dengan survei resep pasien rawat \\ jalan Jamkesmas, rekam medis, SPM, \\ formularium Jamkesmas dan transaksi \\ penjualan. sedangkan pengambilan data \\ kualitatif dengan wawancara mendalam \\ dilakukan untuk melengkapi data. Penelitian \\ dilakukan di Instalasi Farmasi Rawat Jalan pada \\ salah satu Rumah Sakit di Daerah Istimewa \\ Yogyakarta (RS X). \\ Sampel yang digunakan adalah resep \\ pasien rawat jalan Jamkesmas dalam kurun
}

waktu tiga bulan, terhitung sejak bulan Januari sampai Maret 2011. Jenis penyakit meliputi ISK, CHF, DM, PKTB, Hipertensi, Low back pain, Stroke, Epilepsi, Vertigo, dan Migrain. Besar sampel untuk masing-masing penyakit adalah seluruh resep dengan diagnosis tunggal.

Kesesuaian resep dengan SPM dan formularium Jamkesmas dihitung untuk setiap diagnosa dari 10 penyakit yang diteliti. Perhitungan tersebut menggunakan rumus indikator penggunaan obat menurut World Health Organization (WHO). Persentase kesesuaian resep obat dengan Standar Pelayanan Medis (SPM) diperoleh dari perbandingan antara jumlah resep yang sesuai dengan SPM dibagi dengan total jumlah resep yang diamati. Satu resep dikatakan sesuai dengan SPM apabila seluruh item obat dalam resep sesuai dengan SPM. Sedangkan, persentase obat yang diresepkan sesuai dengan formularium Jamkesmas adalah perbandingan antara jumlah obat yang sesuai dengan formularium Jamkesmas dibagi dengan total jumlah obat yang diresepkan pada resep yang diamati (WHO, 1993).

Selain itu juga dilakukan evaluasi penggunaan obat secara menyeluruh pada seluruh resep 10 penyakit yang diteliti dengan menggunakan indikator penggunaan obat menurut $\mathrm{WHO}$, meliputi jumlah rata-rata obat per lembar resep, persentase penggunaan obat generik, persentase obat antibiotik, persentase obat sediaan injeksi, persentase obat sesuai DOEN serta biaya untuk obat antibiotik dan obat sediaan injeksi.

Pengumpulan data kualitatif dilakukan dengan cara wawancara mendalam kepada 
Kepala Instalasi Farmasi dan Staf Medis Fungsional (dokter penulis resep yang diteliti) dengan menggunakan sebuah pedoman pertanyaan. Pengambilan data dilakukan setelah data kuantitatif diperoleh.

\section{HASIL PENELITIAN DAN PEMBAHASAN}

Standar Pelayanan Medis digunakan sebagai pedoman terapi di RS X. Khusus pasien Jamkesmas, tindakan-tindakan pelayanan kesehatan dilakukan berdasarkan pada SPM RS $X$ dan obat yang diberikan disesuaikan dengan formularium Jamkesmas. Penggunaan SPM dan formularium Jamkesmas tersebut bertujuan untuk mewujudkan pengobatan yang rasional, yaitu suatu pengobatan yang bermutu, aman, dan terjangkau.

Kesesuaian resep terhadap SPM pada pasien Jamkesmas di RS X dapat dilihat pada
Tabel. 1. Rata-rata kesesuaian resep dengan SPM yang paling tinggi terdapat pada penyakit Diabetes Mellitus sebesar $82 \%$. Hal menunjukkan bahwa obat yang diresepkan sebagian besar sudah sesuai dengan SPM. Terapi penyakit Diabetes Mellitus pada SPM menggunakan obat antidiabetes golongan sulfonilurea, biguanid, tiazolidindion, penghambat glukosidase alfa, glitazon dan insulin. Pada penyakit Diabetes Mellitus, obat yang paling banyak diresepkan yaitu metformin dan glibenklamid, karena obat antidiabetes yang terdapat dalam formularium Jamkesmas hanya metformin, glibenklamid, dan glipizid. Dokter tidak meresepkan glipizid karena obat tersebut tidak tersedia di instalasi farmasi RS $\mathrm{X}$. Sedangkan pada penyakit $\mathrm{CHF}$, rata-rata persentase kesesuaian sangat rendah sebesar $24,3 \%$ karena adanya peresepan $\mathrm{KCl}$ yang tidak terdapat dalam SPM di RS X. Berdasarkan

Tabel 1. Kesesuaian Resep Dengan SPM Pada Pasien Rawat Jalan Jamkesmas Bulan Januari - Maret 2011 di RS X

\begin{tabular}{|c|c|c|c|c|c|c|c|c|}
\hline \multirow[t]{2}{*}{ No } & \multirow[t]{2}{*}{ Penyakit } & \multicolumn{3}{|c|}{ Jumlah lembar R/ } & \multicolumn{3}{|c|}{$\begin{array}{c}\% \text { Kesesuaian resep dengan } \\
\text { SPM }\end{array}$} & \multirow[t]{2}{*}{$\begin{array}{l}\text { Rata-rata \% } \\
\text { kesesuaian } \\
\text { resep dengan } \\
\text { SPM } \pm(\mathrm{SD})\end{array}$} \\
\hline & & Jan & Feb & Maret & Jan & Feb & Maret & \\
\hline 1 & LBP & 68 & 62 & 53 & 66 & 62 & 64 & $64 \pm 2$ \\
\hline 2 & Epilepsi & 63 & 38 & 68 & 66 & 52 & 73 & $63.6 \pm 10.6$ \\
\hline 3 & PKTB & 51 & 51 & 40 & 37 & 35 & 27 & $33 \pm 5.2$ \\
\hline 4 & DM & 33 & 37 & 32 & 81 & 75 & 90 & $82 \pm 7.5$ \\
\hline 5 & ISK & 34 & 24 & 35 & 32 & 29 & 34 & $31.6 \pm 23.7$ \\
\hline 6 & $\mathrm{CHF}$ & 25 & 27 & 33 & 24 & 25 & 24 & $24.3 \pm 0.5$ \\
\hline 7 & Hipertensi & 29 & 19 & 26 & 55 & 26 & 73 & $50.6 \pm 23.7$ \\
\hline 8 & Migrain & 22 & 21 & 16 & 68 & 76 & 87 & $77 \pm 9.5$ \\
\hline 9 & Stroke & 18 & 14 & 27 & 50 & 43 & 44 & $45.6 \pm 3.7$ \\
\hline 10 & Vertigo & 18 & 17 & 12 & 44 & 70 & 58 & $57.3 \pm 13.0$ \\
\hline
\end{tabular}

Keterangan:

LBP : Low Back Pain

CHF : Congestive Heart Failure

DM : Diabetes Mellitus

PKTB : Primer Kompleks Tuberkulosis

ISK : Infeksi Saluran Kemih 
SPM, terapi CHF seharusnya menggunakan ACE-inhibitor, ARB, diuretik, atau digoxin.

Rata-rata persentase kesesuain resep dengan SPM pada penyakit PKTB dan ISK juga rendah yaitu $33 \%$ dan $31.6 \%$ (Tabel 1 ). Pada penyakit PKTB, hal tersebut dikarenakan banyaknya peresepan heptasan dan vitamin B6 yang tidak termasuk dalam SPM RS X. Terapi penyakit PKTB pada SPM RS $X$ terdiri dari isoniazid, rifampicin, pirazinamida, etambutol, dan streptomicin injeksi. Rendahnya persentase kesesuaian resep dengan SPM penyakit ISK disebabkan karena dokter banyak meresepkan parasetamol. Berdasarkan SPM RS X, terapi untuk penyakit ISK dapat menggunakan antibiotik secara empiris dan terapi suportif seperti antispasme. Hal ini sesuai dengan Nicolle, et al. (2006) bahwa first-choice untuk terapi ISK adalah antibiotik trimetoprimsulfametoxazol. Namun dengan adanya peningkatan resistensi terhadap trimetoprimsulfametoxazole, maka digunakan golongan fluorokuinolon. Begitu juga pada resep untuk penyakit ISK, obat antibiotik yang paling banyak diresepkan yaitu siprofloksasin dan cefixim sebesar $37.6 \%$ dan $40.8 \%$. Berdasarkan uraian tersebut, dapat disimpulkan bahwa resep yang ditulis oleh dokter pada sepuluh penyakit yang diteliti belum sepenuhnya sesuai dengan SPM.

Pada pasien Jamkesmas, obat yang dipilih harus sesuai dengan formularium Jamkesmas, karena pemilihan obat-obat tersebut telah berdasarkan pada manfaat, keamanan, ketepatan, dan keterjangkauan sesuai dengan DOEN (Anonim, 2008). Rata-rata persentase kesesuaian obat yang diresepkan pada 10 penyakit pasien rawat jalan Jamkesmas di RS X bervariasi, yaitu sebesar 49\%-96\% (Tabel 2). Pada penelitian ini, ratarata persentase kesesuaian resep dengan formularium Jamkesmas terendah ada pada penyakit vertigo (49\%). Hal ini disebabkan karena dokter banyak meresepkan Versilon® atau betahistin mesilat yang tidak termasuk dalam formularium Jamkesmas.

Berdasarkan hasil wawancara dengan Kepala Instalasi Farmasi Rumah Sakit diketahui bahwa apabila ada dokter yang meresepkan obat di luar formularium Jamkesmas maka dokter harus membuat suatu protokol terapi.

Tabel 2. Kesesuaian Obat Dengan Formularium Jamkesmas Pada Pasien Rawat Jalan Jamkesmas Bulan Januari-Maret 2011 di RS X

\begin{tabular}{|c|c|c|c|c|c|c|c|c|}
\hline \multirow[t]{2}{*}{ No } & \multirow[t]{2}{*}{ Penyakit } & \multicolumn{3}{|c|}{$\begin{array}{l}\text { Jumlah jenis obat } \\
\text { yang di R/ }\end{array}$} & \multicolumn{3}{|c|}{$\begin{array}{l}\text { \% obat yang sesuai dengan } \\
\text { formularium Jamkesmas }\end{array}$} & \multirow[t]{2}{*}{$\begin{array}{l}\text { Rata-rata jenis obat } \\
\text { yang sesuai dengan } \\
\text { FJ }(\%) \pm(\text { SD) }\end{array}$} \\
\hline & & Jan & Feb & Maret & Jan & Feb & Maret & \\
\hline 2 & Epilepsi & 104 & 76 & 107 & 88 & 84 & 83 & $85 \pm 2.6$ \\
\hline 3 & PKTB & 164 & 170 & 145 & 93 & 92 & 88 & $91 \pm 2.6$ \\
\hline 6 & $\mathrm{CHF}$ & 107 & 111 & 137 & 95 & 94 & 94 & $94.3 \pm 0.5$ \\
\hline 7 & Hipertensi & 75 & 49 & 60 & 97 & 95 & 96 & $96 \pm 1$ \\
\hline 8 & Migrain & 102 & 85 & 77 & 83 & 81 & 80 & $81.3 \pm 2$ \\
\hline 9 & Stroke & 55 & 37 & 80 & 56 & 48 & 70 & $58 \pm 11$ \\
\hline 10 & Vertigo & 54 & 42 & 34 & 48 & 52 & 47 & $49 \pm 3$ \\
\hline
\end{tabular}


Pada protokol terapi tersebut, dokter harus menulis diagnosis dengan jelas dan disertai tandatangan dokter serta persetujuan direksi. Jika tidak ada protokol terapi, maka pihak instalasi farmasi tidak melayani obat tersebut. Selain itu, apabila dokter meresepkan obat sesuai dengan formularium Jamkesmas tetapi dalam bentuk obat merek dagang, maka pihak instalasi farmasi dapat mengganti obat merek dagang tersebut dengan obat generik baik secara langsung maupun dengan seizin dokter. Namun demikian, tidak seluruh obat yang termasuk dalam formularium Jamkesmas tersedia dalam bentuk obat generik di RS X. Jika ada peresepan obat merek dagang dan di Instalasi Farmasi RS X tidak menyediakan obat generiknya, maka pasien tetap diberikan obat merek dagang dengan harga terjangkau. Hal ini bertujuan untuk menjaga agar pasien tetap mendapatkan obat sesuai dengan yang dibutuhkan.

Berdasarkan hasil wawancara mendalam dengan Staf Medis Fungsional, ketidaksesuaian peresepan dengan SPM dan formularium Jamkesmas dapat disebabkan karena pasien dalam keadaan darurat, keadaan paramedis pasien yang tidak dapat menerima obat yang sesuai dengan SPM dan formularium Jamkesmas serta adanya permintaan dari pasien untuk meresepkan obat tertentu. Hal ini sama halnya dengan hasil dari penelitian oleh Cabana (1999), yang menyebutkan bahwa ketidakpatuhan prescribers terhadap suatu pedoman pengobatan dapat dipengaruhi oleh kurangnya pengetahuan tentang pedoman pengobatan dan adanya tekanan dari luar, seperti permintaan pasien.

Pada penelitian ini, data berdasarkan pada diagnosis tunggal yang ada pada rekam medis. Pada penelitian Alagappan (2006) disebutkan bahwa rendahnya kesesuaian resep dengan SPM terjadi akibat dokter tidak menulis diagnosis atau gejala-gejala penyakit dan terapi dengan lengkap dan jelas di rekam medis. Salah satu faktor yang mempengaruhi kelengkapan dari rekam medis adalah jumlah pasien yang banyak. Hal tersebut menyebabkan waktu dokter untuk menulis di rekam medis sangat terbatas. Catatan medis, diagnosis yang tidak lengkap, dapat menyebabkan resep yang ditulis tidak sesuai dengan diagnosis yang telah ditetapkan pada SPM. Contohnya seperti pada resep penyakit hipertensi, dokter meresepkan parasetamol untuk mengatasi nyeri dan demam yang diderita pasien, namun diagnosis yang ditulis oleh dokter hanya hipertensi.

Adanya ketentuan penggunaan SPM dan formularium Jamkesmas pada pelayanan kesehatan pasien Jamkesmas juga bertujuan untuk meningkatkan penggunaan obat rasional. Oleh karena itu dilakukan evaluasi penggunaan obat pada 10 penyakit secara keseluruhan dengan menggunakan indikator penggunaan obat menurut WHO. Evaluasi penggunaan obat itu secara tidak langsung bermanfaat untuk meningkatkan mutu pelayanan kesehatan kepada pasien (Matowe and Degnan, 2012). Data hasil evaluasi penggunaan obat tercantum pada Tabel 3. 
Tabel 3. Indikator Penggunaan Obat Pada Sepuluh Penyakit Pasien Rawat Jalan Jamkesmas Bulan Januari-Maret 2011 di RS X

\begin{tabular}{clc}
\hline No & \multicolumn{1}{c}{ Indikator } & Persentase \\
\hline 1 & Jumlah lembar R/ & 1013 \\
2 & Total item obat & 2761 \\
3 & Rata-rata obat per resep & 2,7 \\
4 & Persentase obat generik & $85,7 \%$ \\
5 & Persentase obat & $23,3 \%$ \\
& antibiotik & $22.0 \%$ \\
6 & Persentase obat injeksi & $76,7 \%$ \\
7 & Persentase obat yang & \\
\hline & masuk DOEN & \\
\hline
\end{tabular}

Pada Tabel 3. dapat dilihat bahwa jumlah obat rata-rata per resep sebesar 2,7, angka tersebut masih di atas persyaratan jumlah obat rata-rata per resep yang direkomendasikan oleh WHO yaitu 2. Hasil tersebut menunjukkan bahwa masih terdapat polifarmasi yang dapat menyebabkan terjadinya adverse drug reactions, penurunan terhadap kepatuhan pengobatan, dan penggunaan obat yang tidak perlu (Ghimire et al., 2009).

Persentase peresepan obat generik pada pasien rawat jalan Jamkesmas sudah memenuhi standar (>80\%). Salah satu tujuan peresepan obat generik adalah untuk meningkatkan keterjangkauan biaya oleh pasien, terutama pasien Jamkesmas (Anonim, 2010b).

Persentase penggunaan sediaan injeksi pada pasien rawat jalan Jamkesmas sebesar 22\%, lebih tinggi dari rekomendasi WHO. Menurut WHO, peresepan sediaan injeksi yang mengandung satu atau lebih jenis sediaan injeksi seharusnya kurang dari sepuluh persen. Hasil tersebut menunjukkan bahwa penggunaan obat sediaan injeksi di RS $\mathrm{X}$ belum rasional.
Pada penelitian ini, penggunaan sediaan injeksi paling banyak terjadi pada peresepan untuk penyakit LBP sebesar $61,2 \%$ dari seluruh kasus penyakit LBP yang diteliti. Penggunaan sediaan injeksi yang tinggi pada penyakit LBP disebabkan karena banyaknya peresepan ketorolac yang berfungsi sebagai antiinflamasi dan analgesik. Banyaknya pasien yang meminta atau menekan dokter untuk memberikan obat suntik juga menjadi salah satu penyebab tingginya peresepan sediaan injeksi. Penggunaan injeksi dapat menyebabkan peningkatan risiko sepsis, iritasi, infeksi melalui rute parenteral dan biaya terapi yang mahal atau sulit terjangkau (Ghimire et al., 2009; Angamo et al., 2011).

Tabel 4. Persentase Biaya untuk Obat Antibiotik dan Injeksi pada Resep Sepuluh Penyakit Pasien Rawat Jalan Jamkesmas Bulan Januari-Maret 2011 di RS X

\begin{tabular}{clcc}
\hline No & Indikator & Biaya (Rp) & $\begin{array}{c}\text { Persentase } \\
(\%)\end{array}$ \\
\hline 1 & $\begin{array}{l}\text { Total biaya } \\
\text { seluruh resep }\end{array}$ & 47.562 .880 & 100 \\
2 & $\begin{array}{l}\text { Biaya untuk } \\
\text { obat antibiotic }\end{array}$ & 9.047 .577 & 23.4 \\
3 & $\begin{array}{l}\text { Biaya untuk } \\
\text { obat injeksi }\end{array}$ & 15.852 .81 & 41.0 \\
\hline
\end{tabular}

Persentase penggunaan antibiotik dan penggunaan injeksi dapat digunakan untuk memperkirakan besar biaya yang dibutuhkan dalam pengadaan antibiotik dan obat sediaan injeksi. Biaya untuk antibiotik sebesar 23,4\% dari total biaya obat pada seluruh resep yang diteliti, sedangkan biaya untuk obat sediaan injeksi sebesar 41,0\% (Tabel 4.). Penggunaan sediaan injeksi yang tinggi akan berdampak 
pada biaya yang digunakan untuk pengadaan obat di IFRS. Biaya sediaan injeksi untuk 10 penyakit yang diteliti sebesar $41.0 \%$, nilai ini berarti bahwa biaya yang dibutuhkan untuk mencukupi kebutuhan obat injeksi sebesar $41.0 \%$ dari seluruh biaya yang dibutuhkan untuk memenuhi kebutuhan obat pada 10 penyakit . Penggunaan obat injeksi sebaiknya lebih diminimumkan untuk menghindari infeksi melalui parenteral dan menurunkan biaya obat per lembar resep, agar lebih terjangkau. Selain itu, juga untuk meminimalkan biaya pengadaan obat injeksi, sehingga biaya yang ada dapat digunakan untuk mengadakan obat-obat lain yang lebih dibutuhkan.

\section{KESIMPULAN}

Berdasarkan uraian di atas, dapat disimpulkan bahwa peresepan untuk sepuluh penyakit yang diteliti pada pasien Jamkesmas di RS X, belum sepenuhnya sesuai dengan SPM dan formularium Jamkesmas. Dan secara tidak langsung, penelitian ini juga menunjukkan adanya beberapa penggunaan obat yang belum rasional, seperti .jumlah obat per lembar resep dan penggunaan obat sediaan injeksi.

\section{DAFTAR PUSTAKA}

Adisasmito, W., 2008, Kebijakan Standar Pelayanan Medik dan Diagnosis Related Group (DRG), Kelayakan Penerapannya dilndonesia. <http://staff.blog.ui.ac.id/wikua/files/2009/02/kebijakan-standarpelayanan-medik-drg_edited.pdf> (diakses 20 Juni 2011)

Alagappan, K., Pulido, G., Caldwell, J., Abrahamian, F.M., 2006, Physician Compliance with Tetanus Guidelines for
Admitted Versus Discharged Patients, Southern Medical Journal, March; 99 (3): 234-238

Angamo, M.T., Wabe, N.T., Raju, N.J., 2011, Assessment of Pattern of Drug Use by Using World Health Organation's Prescribing, Patient Care and Health Facility Indicators in Selected Health Facilities in Southwest Ethiopia, Journal of Applied Pharmaceutical Science; 01 (07): 62-66

Anonim, 2008, Pedoman Pelaksanaan Jaminan Kesehatan Masyarakat (Jamkesmas), Departemen Kesehatan Republik Indonesia, Jakarta

Anonim, 2010a, Pedoman Pelaksanaan Jaminan Kesehatan Masyarakat (Jamkesmas), Kementerian Kesehatan Republik Indonesia, Jakarta

Anonim, 2010b, Formularium Jamkesmas, Kementerian Kesehatan Republik Indonesia, Jakarta

Cabana, M.D., Rand, C.S., Powe, N.R., Wu, A.W., Wilson, M.H., Abboud, P.C., Rubin, H.R., 1999, Why Don't Physicians Follow Clinical Practice Guidelines? A Framework For Improvement, JAMA October; 282 (15): 1458-1465

Fijn, R., Lenderink, A.W., Egberts, A.C.G., Brouwers, J.R.B.J., DenBerg, L.T.W.D.J., 2001, Assesment of indicators for hospital formulary non-adherence, Eur $J$ Clin Pharmacol 57: 677-684

Fitriah, R., 2012, Evaluasi Kerasionalan Penggunaan Obat dengan Standar Pelayanan Medis sebagai Pengendali Pada Beberapa Penyakit di RSUD Panembahan Senopati Bantul, Tesis, Pascasarjana IImu Kesehatan Masyarakat, Universitas Gadjah Mada, Yogyakarta

Ghimire, S., Nepal, S., Bhandari, S., Nepal, P., Palain, S., 2009, A Prospective Surveillance of drug prescribing and dispensing in a teaching hospital in Western Nepal, J Pak Med Assoc; 59 (10): 726-730 
Matowe, L. and Degnan D.R., 2012 , "Investigating Medicine Use" in Managing Access to Medicines and Health Technologies, $3^{\text {rd }}$ ed. United Stated of America: Management Sciences for Health, Inc.

Nicolle, L., Anderson, P., Conly, J., Mainprize, T.C, Meuser, J., Nickel, J.C, Senikas, V.M, Zhanel, C.G, 2006, Uncomplicated urinary tract infection in woman, Canadian Family Physician May; Vol 52: 612-618.

WHO, 1993, How to Investigate Drug Use in Health Facilities, World Health Organization Action Programme on Essensial Drugs, Geneva, Switzerland 